\title{
Application of a hybrid model of neural networks and genetic algorithms to evaluate landslide susceptibility
}

\author{
H. B. Wang ${ }^{1,2^{*}}$, J. M. Li ${ }^{1}$, B. Zhou' ${ }^{1}$ Y. Zhou' ${ }^{1}$ Z. Q. Yuan ${ }^{1}$ and Y. P. Chen ${ }^{3}$
}

\begin{abstract}
Background: In the last few decades, the development of Geographical Information Systems (GIS) technology has provided a method for the evaluation of landslide susceptibility and hazard. Slope units were found to be appropriate for the fundamental morphological elements in landslide susceptibility evaluation.

Results: Following the DEM construction in a loess area susceptible to landslides, the direct-reverse DEM technology was employed to generate 216 slope units in the studied area. Of the 216 slope units, 123 involved landslides. To analyze the mechanism of these landslides, six environmental factors were selected to evaluate landslide occurrence: slope angle, aspect, the height and shape of the slope, distance to river and human activities. The spatial analysis demonstrates that most of the landslides are located on convex slopes at an elevation of 100$150 \mathrm{~m}$ with slope angles from $135^{\circ}-225^{\circ}$ and $40^{\circ}-60^{\circ}$. Landslide occurrence was then checked according to these environmental factors using an artificial neural network with back propagation, optimized by genetic algorithms. A dataset of 120 slope units was chosen for training the neural network model, and the parameters of genetic algorithms and neural networks were set.
\end{abstract}

Conclusion: After training on the datasets, the susceptibility of landslides was mapped for the land-use plan and hazard mitigation. Comparing the susceptibility map with landslide inventory, the verification shows satisfactory agreement with an accuracy of $86.46 \%$ between the susceptibility map and the landslide locations. In the landslide susceptibility assessment, ten new slopes were predicted to show potential for failure, which can be confirmed by the engineering geological conditions of these slopes.

Keywords: Landslide, Geographical Information Systems, Genetic algorithms, Back propagation neural networks, Susceptibility evaluation

\section{Background}

Landslides are local phenomena occurring in different geomorphic contexts; they can be triggered by a variety of mechanisms, such as earthquakes or rainfall, and some of the causes are not yet well known. Landslides cannot be predicted accurately; however, the susceptibility of a given area to landslides can be determined and depicted using hazard zonation. Various methods have been proposed to partition landscape for the purpose of landslide

\footnotetext{
* Correspondence: huabin@mail.hust.edu.cn

'School of Civil Engineering and Mechanics, Huazhong University of Science \& Technology, Wuhan 430074, People's Republic of China

${ }^{2}$ Hubei Key Laboratory of Control Structure, Huazhong University of Science

\& Technology, Wuhan 430074, People's Republic of China

Full list of author information is available at the end of the article
}

hazard assessment and zonation mapping, including grid cells, terrain units, unique-condition units, slope units and topographic units (Carrara et al. 1991; van Westen, 1994; Guzzetti et al. 1999; Chung and Fabbri, 2003). With respect to the landscape partitioning methods mentioned above, slope units can be resized according to the prevailing failure type and dimension, thereby partitioning a river basin into nested subdivisions: coarser for larger landslides and finer for smaller failures. Because a clear physical relationship exists between landslides and the fundamental morphological elements of a hilly or mountain region, namely, drainage and divided lines, the slope-unit technique seems appropriate for landslide susceptibility assessment. 
A careful review of the concepts, principles, techniques and methodologies for landslide susceptibility evaluation reveals that the most commonly used methods are geomorphological hazard mapping, analysis of landslide inventories, heuristic or index-based methods, functional, statistically based models and geotechnical or physically based models (Guzzetti et al. 1999; Wang et al. 2005; Fell et al., 2008). Recently, probabilistic models such as frequency ratio and logistic regression methods have been applied to evaluate landslide susceptibility and have been integrated with Geographical Information Systems (GIS) (Ayalew and Yamagishi, 2005; Chung, 2006; Dahal et al., 2008; Nefeslioglu, et al., 2008; Yilmaz, 2009; Bai et al. 2011; García-Rodríguez and Malpica, 2010; Hasekiogullar and Ercanoglu 2012; Martinovic et al., 2016). Due to geological complexity of slopes and self-organized system, however, many variables are involved in slope stability evaluation, and these variables display a highly nonlinear relationship with the evaluation results. Under the consideration of the nonlinear characteristics of the sliding process, artificial neural networks (ANNs) have thus been introduced to produce landslide susceptibility and hazard maps (Ercanoglu and Gokceoglu, 2002; Neaupane and Achet, 2004; Catani et al., 2005; Gómez and Kavzoglu, 2005; Kanungoa et al. 2006; Nefeslioglu, et al., 2008; Nefeslioglua et al., 2011).

The main characteristics of ANNs dealing with quantitative and qualitative indices include large-scale parallel distributed processing, continuously nonlinear dynamics, collective computation, high fault-tolerance, self-organization, self-learning and real-time treatment (Rumelhart and McClelland 1986). It is worth noting that a neural network system is a processing device, implemented as an algorithm or in hardware, whose design is inspired by the design and the function of mammalian brains; they react to training data input in such a way to alter their initial state, and they learn using unconventional algorithms. Neural networks integrated with GIS may be an effective approach when dealing with landslide hazard assessments where meaningful outcomes are difficult to achieve by means of standard mathematical models. Because artificial neural network models are adaptive and capable of generalization, they can handle imperfect or incomplete data and can capture nonlinear and complex interactions among the several variables of a system (Ermini et al. 2005; Melchiorre et al. 2008; Lee and Pradhan 2010; Conforti et al., 2014; Pham et al., 2017).

However, it was found that the slow training speed and difficulty in achieving a local minimum cannot be resolved in practical applications for the most commonly used back propagation neural networks (BPNN). To solve this problem, several methods were proposed to improve the training speed of networks, such as improving error functions and adjusting the studying rates. For this kind of solutions, the BPNN is likely to converge to a local solution, which may not be the global solution, with the random selection of initial weights. Thus, a global search algorithm was then introduced, e.g., evolutionary programming, simulated annealing or genetic algorithms (GAs) (Kavzoglu et al., 2015). Among them, GA has mainly been used to search for the optimal solution in BPNNs due to its excellent global search ability (Holland 1975; Sexton and Gupta, 2000; Kesign, 2004; Madaeni, et al., 2010; Nourani, et al., 2014). There are two main aspects of applying GA to BPNNs for finding global optima in complex problems: one is to optimize the weights of the network, and the other is to optimize the topological structure of the network.

After an overview on landslide susceptibility using ANNs, it was noted that the weights were randomly selected and that the optimization cannot be carried out for global searching. This paper thus proposes a hybrid model of a GA and BPNN to evaluate landslide susceptibility for the optimization of weights. In this study, landslide inventory was mapped after detailed field investigation and interpretation from high-resolution imagery. The outline of the watershed polygons was mapped as the ridge line using DEM, and reverse DEM data were used to detect the valley line. The combined DEM and reverse DEM, slope units were then mapped within ArcGIS. After the definition of slope units, environmental factors were analyzed for the presence of landslide occurrence, and a hybrid of GA and BPNN was developed to evaluate landslide susceptibility. In this method, the GA was used to search for the optimal or approximately optimal connection weights and thresholds for the networks, and then, using back-propagation learning rules and training algorithms, the final weights could be adjusted.

\section{Study area}

The study area is the Changshou Valley, which is located northwest of Baoji city in Shaanxi Province (Fig. 1). The elevation is approximately 600-700 m, and the relative relief exceeds 100-350 m over the Changshou valley. In this area, three main geomorphological units may be distinguished: dissected loess plateau (yuan), loess hills (mao), and loess ridges (liang). The lithology of the strata in these units is mainly Neogene argillites and fluvial deposits consisting of clayey silts and gravels and Quaternary loess. The Yujian stream flows into the Weihe. Due to the erosion of the Pliocene lacustrine basin by stream systems and the reactivation of folds and faults, a very unstable base was formed for the extensive Quaternary loess deposits, which acts as the underlying cause of the loess instability. Steep slopes around the dissected loess plateau can be present in loess falling, 


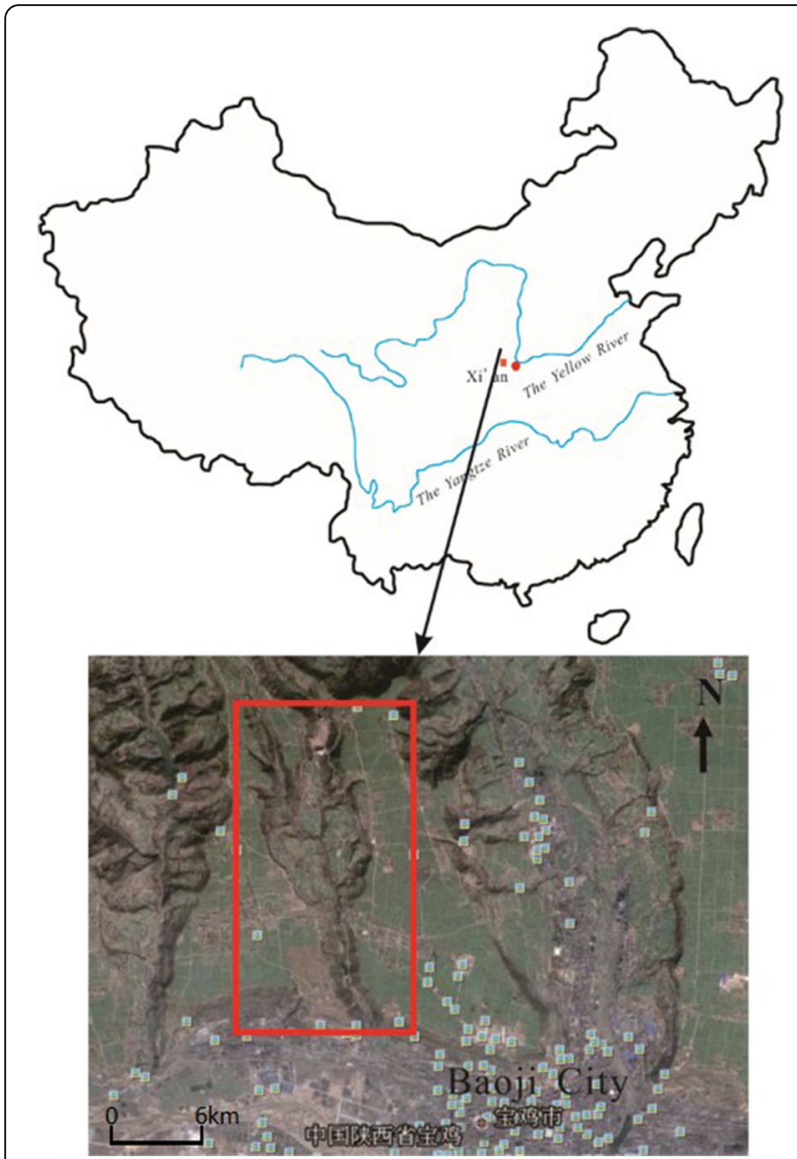

Fig. 1 Geographical location of the study area marked by the red rectangle (data from Google earth)

debris flow and translational slides. Five terraces of the studied area are present in different slope angles, for example, the slope of the fifth terrace is very steep between 30 and $45^{\circ}$, while the slope angle of the third terrace is from 26 to $30^{\circ}$. For the main lithology, loess is known as a "problem soil"; although it can sustain nearly vertical slopes when dry, it is susceptible to catastrophic failure on reaching certain critical moisture contents. The underground water is originally from the infiltration and water in rock joints. It can be divided into different hydrological units due to characteristics of geomorphology and aquifer structure, including units in high terrace, low terrace, sliding area and Pliocene stratum.

Historical records show that three earthquakes with Ms $\geq 8$ occurred on Loess Plateau, which triggered numerous landslides in loess areas (Zhang et al. 1995; Derbyshire et al. 1999). However, only three earthquakes with around Ms 3.5 have been recorded in the study area.

The climate of the study area is notable for Asiatic monsoons and marked seasonal shifts in dominant winds. The mean annual temperature is $12.9{ }^{\circ} \mathrm{C}$, and the maximum is up to $41.6{ }^{\circ} \mathrm{C}$. The mean annual precipitation reaches $679.1 \mathrm{~mm}$, and almost 50\% of the precipitation falls in the period from July to September.

\section{Data preparation}

Landslide inventory

A landslide-inventory map was prepared primarily by the interpretation of high-resolution imagery and secondarily by site investigations. As shown in Fig. 2, 39 landslides in the study area are classified into three types: paleolandslides, old landslides and recent landslides (Meng et al. 2000). Fifty percent of landslides are old as dormantmature, and $25 \%$ have been reactivated recently. For all of the landslides, the slope after failure averages $22.6^{\circ}$, with a maximum of $45^{\circ}$. The slope gradients of large-scale landslides tend to be gentle, at approximately $18^{\circ}$, which implies that most of the paleo-landslides in the study area are stable.

It was also observed that the landslides are concentrated at the confluence of two streams. As described in

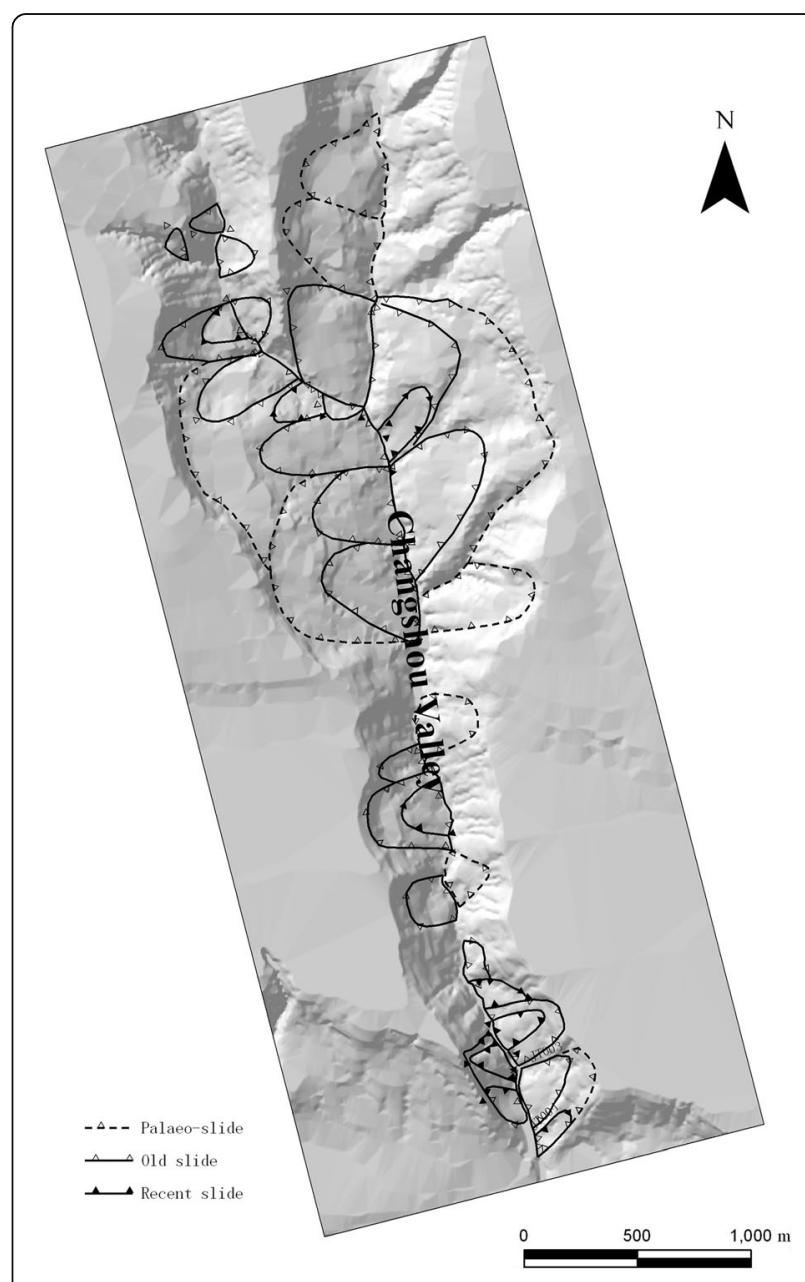

Fig. 2 Landslide inventory mapping in the Changshougou valley 
the previous section, these landslides are attributed to the undercutting of the slopes associated with gullying. Major factors affecting the initiation of slope failure and subsequent modes of movement appear to be dependent upon the morphology, the nature and degree of weathering of the underlying bedrock, and the moisture status of the loess deposits. Numerous ancillary factors include bedrock-loess interface, slope steepness, vegetation cover, and land utilization. As already noted, the upper surface of the Neogene bedrock is often weathered and contains variable amounts of smectites. In this zone, wetting-drying results in a progressive decrease in strength that may ultimately lead to slope failure. Undercutting of the slopes along the gullies is frequent, which increases the risk of slope failure. As a result of the high relative relief, the steep slopes and the relatively uniform geological and geomorphological conditions, the landslides tend to be very large and to occur in groups.

In terms of geological periods, landslides in the studied area fall into three categories: palaeo-slides, old slides, and recent slides. The most ancient landslides are not traceable in the historical records, and some recent landslides keep moving. Typically, a swarm of landslides is located at Zhuyuan village (Fig. 3), approximately $10 \mathrm{~km}$ north of Baoji. The landslide mass is $1000 \mathrm{~m}$ wide and $850 \mathrm{~m}$ long, with an estimated volume of $5.1 \times 10^{7} \mathrm{~m}^{3}$. Steeper slopes are generally over $40^{\circ}$ around the crest, with forested landslide terraces. Remote-sensing interpretations and field investigations indicate a maximum

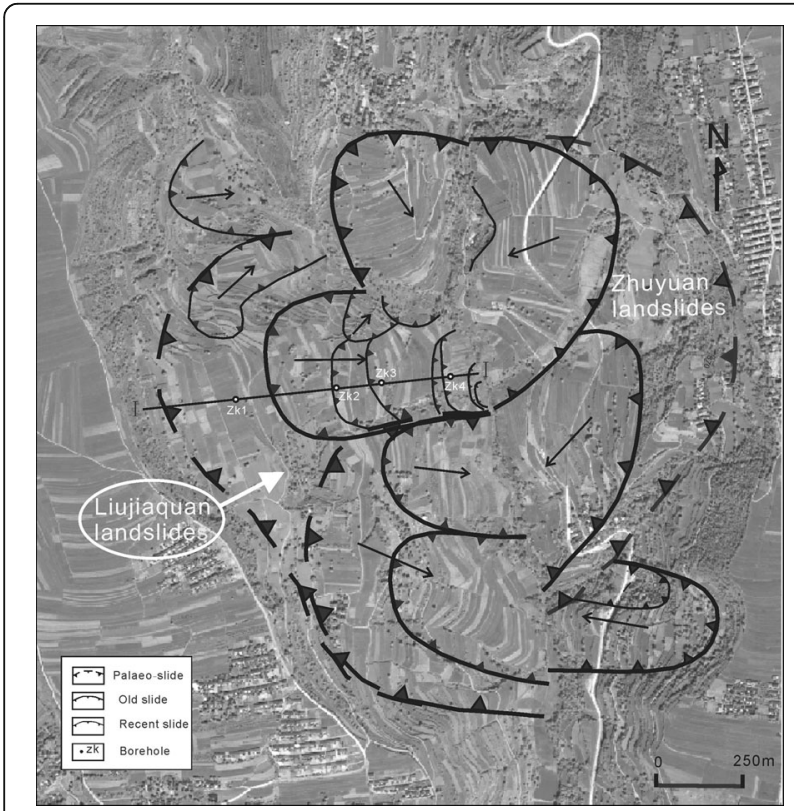

Fig. 3 View of the Zhuyuan and Lijiaquan landslides from a Quickbird image vertical displacement of $150 \mathrm{~m}$ along the slip surface of the landslides. The shape and slope angle of the landslide scars suggest a single, major semi-circular failure plane. For these studied landslides, the failure planes occurred either along the contacts between the fluvial deposits and the Neogene argillites or partially within the bedrock. With regard to the Neogene argillite in the loess plateau, the clay minerals are dominated by illite, chlorite, smectite, and kaolinite, similar to the overlying Quaternary loess (Peng and Guo 2007). This type of argillite is thus subjected to long-term softening due to saturation in the contact zone. After a point is reached, at which they are no longer able to support the overlying loess, a progressive failure occurs. The occurrence of planar slides in the study area depends on the shear-strength conditions of the failure surface and the cohesion of the materials involved, usually presented in the Malan loess and in reworked loess slope deposits.

\section{Defining slope units}

In this study, a GIS-based hydrologic analysis and modeling tool, Arc Hydro, is employed to draw the dividing lines for forming slope units automatically. Arc Hydro is an ArcGIS based software geared to support water resources applications (Maidment et al. 2002). The software provides a method for the delineation of watersheds and stream networks using digital elevation models (DEM) of land-surface terrain. In the present study, the topographic maps were used to produce DEM with a contour interval of $10 \mathrm{~m}$ at a scale of 10,000 . Using the DEM, the outlines of the watershed polygons are topographically mapped as the ridge lines, and the reverse DEM data can be used to detect the valley lines (Xie et al. 2004). Using the DEM grid analysis, high DEM values can be turned into low values and low DEM values to high. After these values change, the original valley line can be turned into a ridge line. Meanwhile, the valley line can also be obtained by watershed analysis of the reverse DEM data. The combined DEM and reverse DEM analyses map the slope units within the scope of ArcGIS in the studied area (Fig. 4).

\section{Selection of environmental factors}

In these slope units, a variety of environmental factors such as, slope angle, aspect, height and the shape of slope were selected to evaluate landslide susceptibility. Two more environmental factors were selected, namely, distance to river and human activities.

\section{(1) Slope angle}

Using the function of Mean in the ArcGIS Spatial Analyst model, an average slope angle was defined 


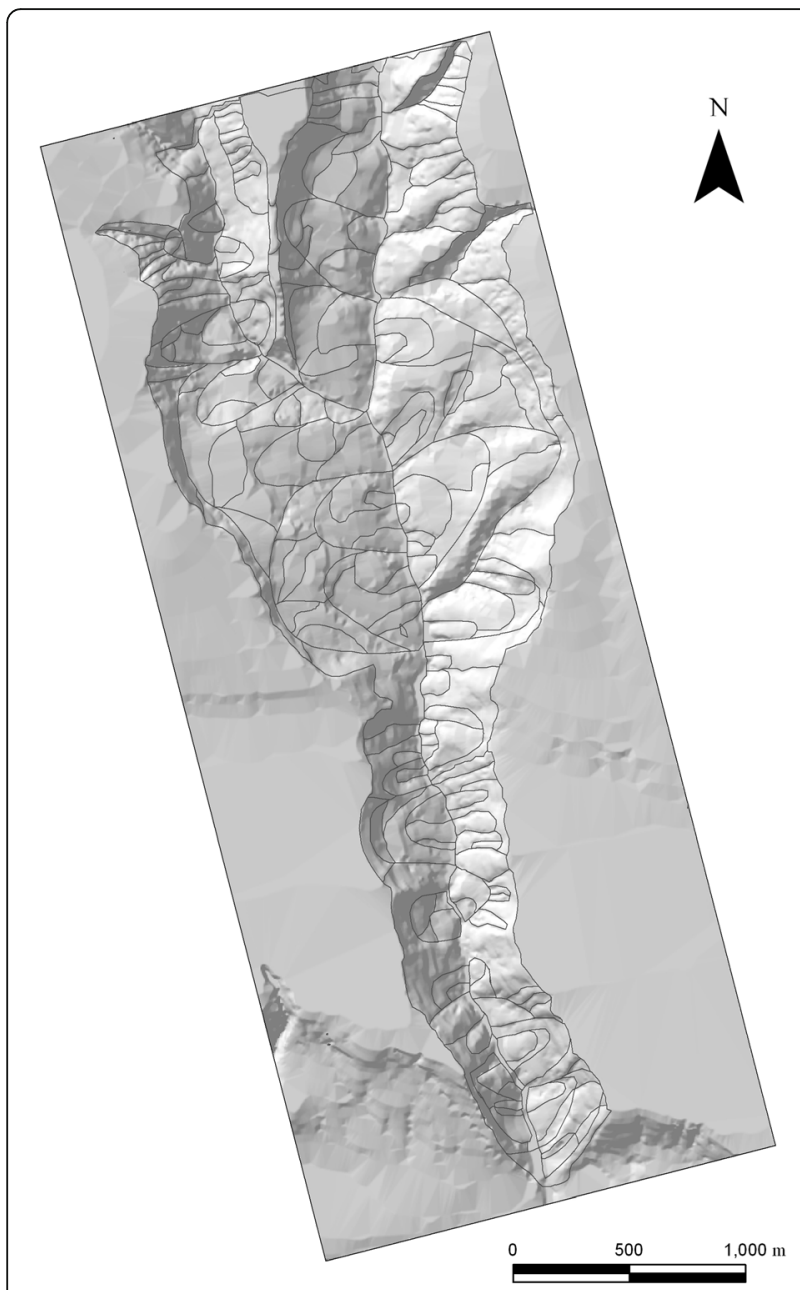

Fig. 4 Slope units from combination of DEM and reverse DEM

for each slope unit. In the study area, slope angles were categorized into six classes: $0-20^{\circ}, 21^{\circ}-30^{\circ}$, $31^{\circ}-40^{\circ}, 41^{\circ}-50^{\circ}, 51^{\circ}-60^{\circ}$ and larger than $60^{\circ}$ (Fig. 5).

(2) Slope height

Slope height plays an important role in landslide occurrence, especially in loess areas. Considering only the slope height for slope failures, higher slopes can increase stress values in different areas of slope, making the slopes unstable. The slope height was classified into five classes: $0-50 \mathrm{~m}$, 51-100 m, 101-150 m, 151-200 m and 201-300 m (Fig. 6). Using Min and Max functions in the model of ArcGIS Spatial Analyst, the slope height was obtained from the difference of the minimum and maximum elevation.

(3) Slope aspect

The slope aspect information can be obtained from the Majority function within the ArcGIS. Aspect

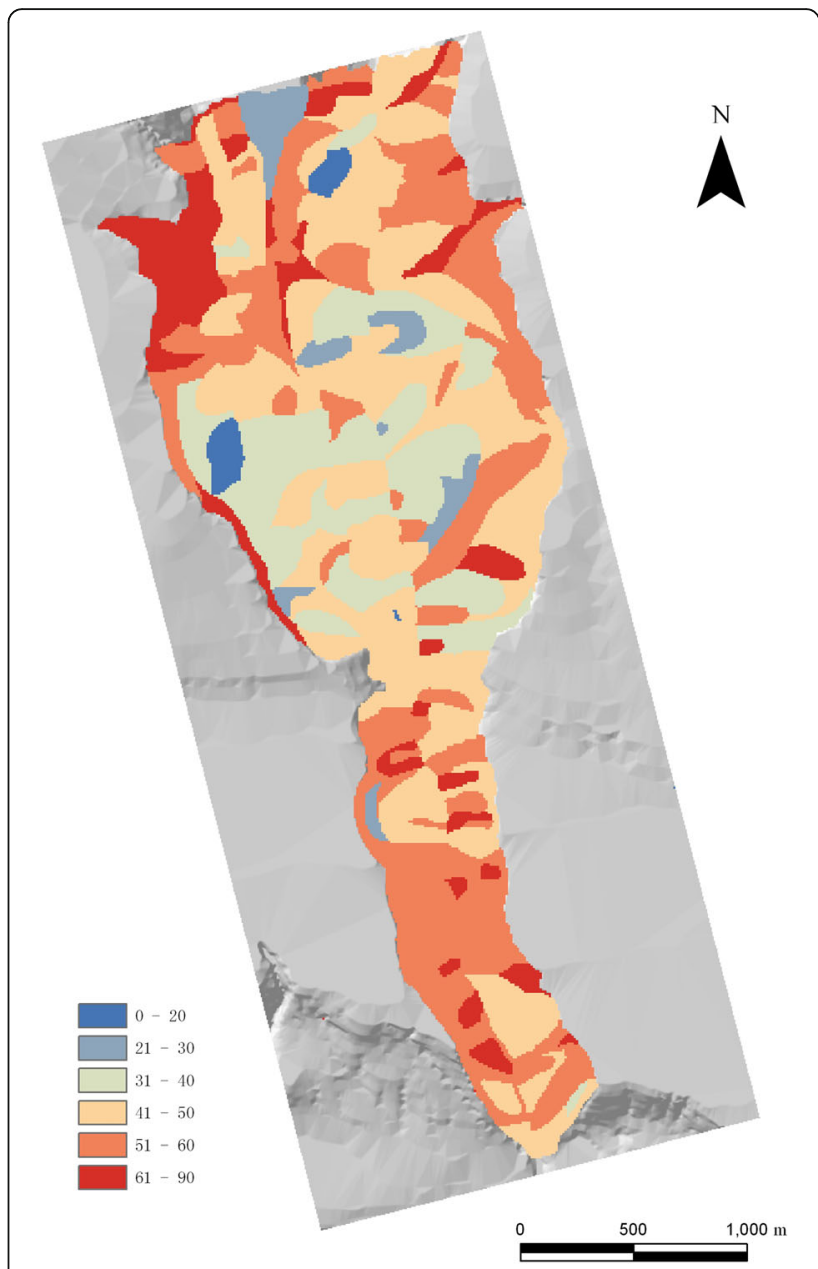

Fig. 5 Thematic map of the slope angle

was categorized as $0-15^{\circ}, 16^{\circ}-90^{\circ}, 91^{\circ}-135^{\circ}$, $136^{\circ}-180^{\circ}, 181^{\circ}-225^{\circ}, 226^{\circ}-270^{\circ}, 271^{\circ}-315^{\circ}$ and $316^{\circ}-360^{\circ}$ (Fig. 7).

(4) Slope morphology

It is known that water concentrates in concave topographic positions and makes the slope susceptible to (sub) surface flow as the main hydrological triggering mechanism. According to the analysis of the relationships between the landslide occurrence and slope morphology, however, most of landslides are located in the convex topographic positions (Fig. 8).

(5)Human activities

Human activities influence the susceptibility due to the land use. In the Changshou valley, the land-use is very homogenous. Forests are present closed to the boundary of the loess plateau, upper the slope of the valley. Areas covered by shrubby and herbaceous vegetation are scattered into the study area, while parts of space are open with more vegetation for 


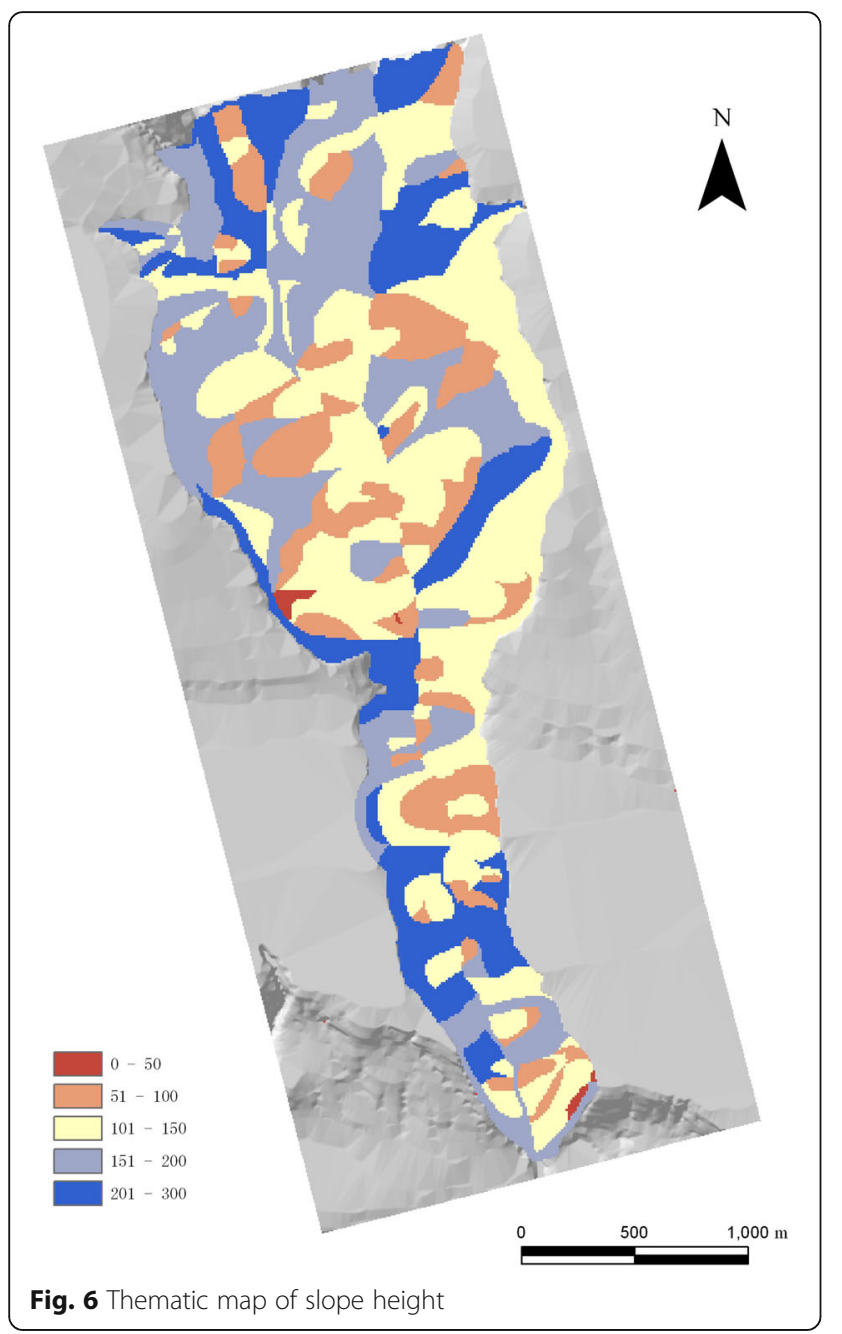

local farmers. In the analysis of human activity, the influence was simply determined by whether the slope area had been used for vegetation or not.

(6) Distance to river

The distance to the river is presented by the proximity of the Changshougou valley and various drainages. These data were obtained from the buffer of rivers and drainages using maps at the scale of 1:25000 in ArcGIS.

\section{Methods}

\section{Normalization of data}

Input-output data for the GA-BPNN training and testing are from a database, including slope, aspect, elevation, shape of slope, distance to river and human activity. These sets are utilized to test network modeling. As the dimension and magnitude of the original sample data are different, the input and test data should be normalized before training, i.e.,

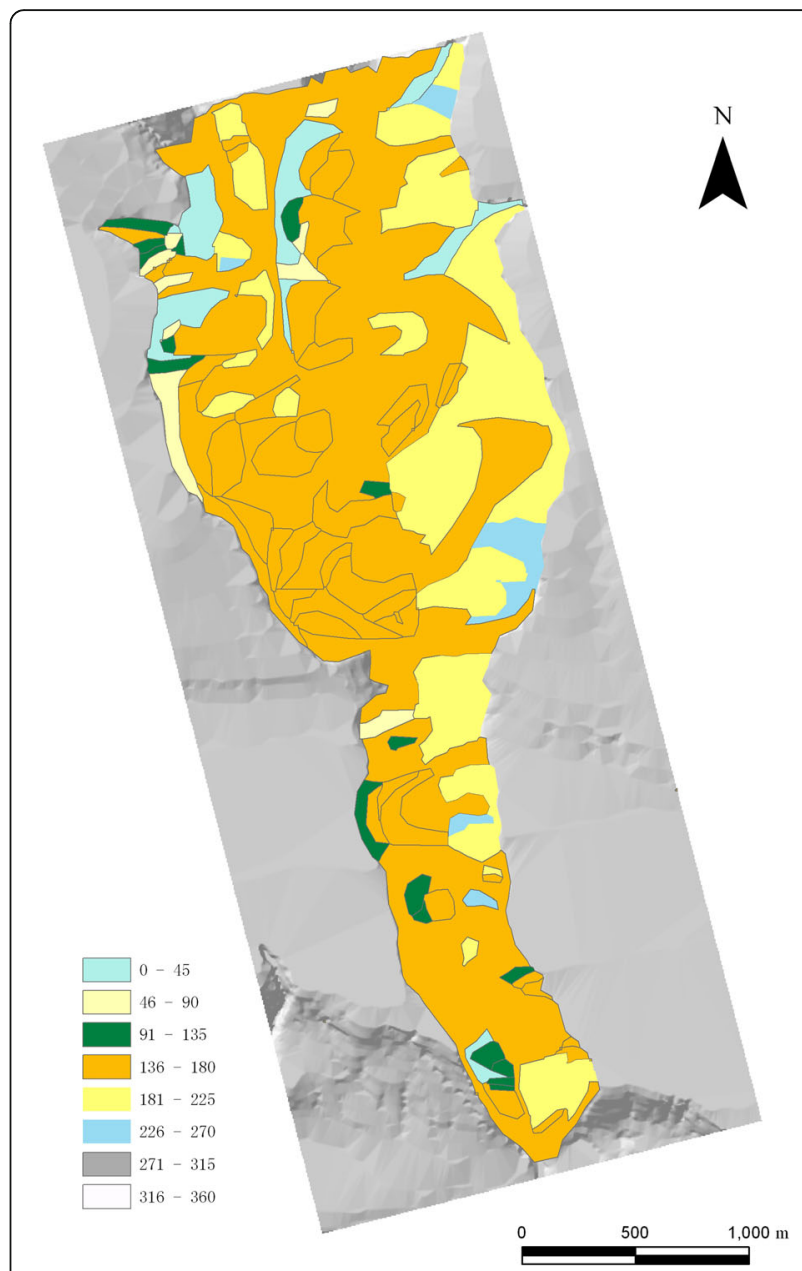

Fig. 7 Thematic map of slope aspect

$$
T=2 \cdot \frac{X-X_{\min }}{X_{\max }-X_{\min }}-1
$$

where $X$ represents the original data, $X_{\max }$ and $X_{\min }$ are the maximum and minimum of original data, respectively. $\mathrm{T}$ is the target data after normalization.

\section{GA-based BPNN}

The BPNN is trained by repeatedly presenting a series of input/output pattern sets to the networks. The networks gradually learn the input/output relationships of interest by adjusting the network weights to minimize the error between the actual and predicted output patterns of the training sets (Fig. 9). After the learning process is completed, the network weight coefficients cannot be changed. In this model, the usage of networks with only forward calculations is needed in pattern recognition and prediction, and the calculation can be executed very quickly.

The GA-based BPNN learning process consists of two stages (Fig. 10): employing GAs to search for the optimal 


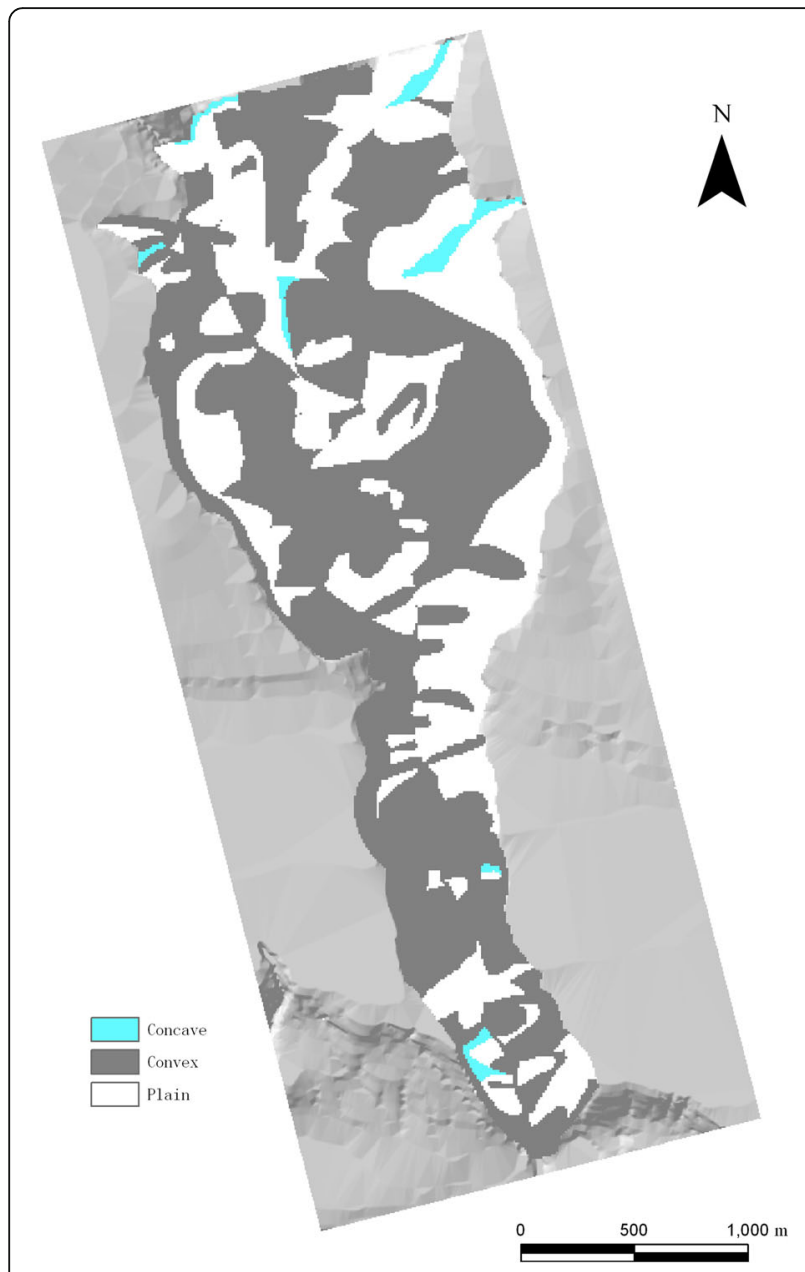

Fig. 8 Thematic map of the slope shape

or approximate optimal connection weights and thresholds for the networks and then using the back-propagation learning rules and training algorithms to adjust the final weights. The implementation procedure of the network training is programmed within Matlab using the GAs and Neural Networks Tool Boxes.

In this method, the BPNN weights and thresholds are represented as genes in a chromosome, and the global optimum is then searched for using the selection,

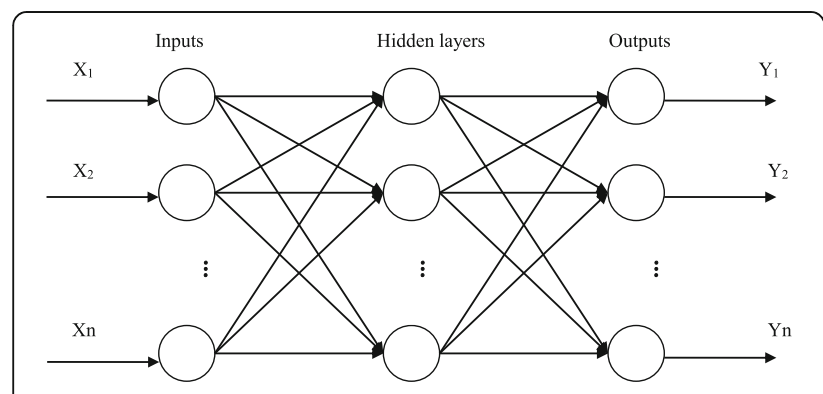

Fig. 9 Architecture of three-layer BPNN

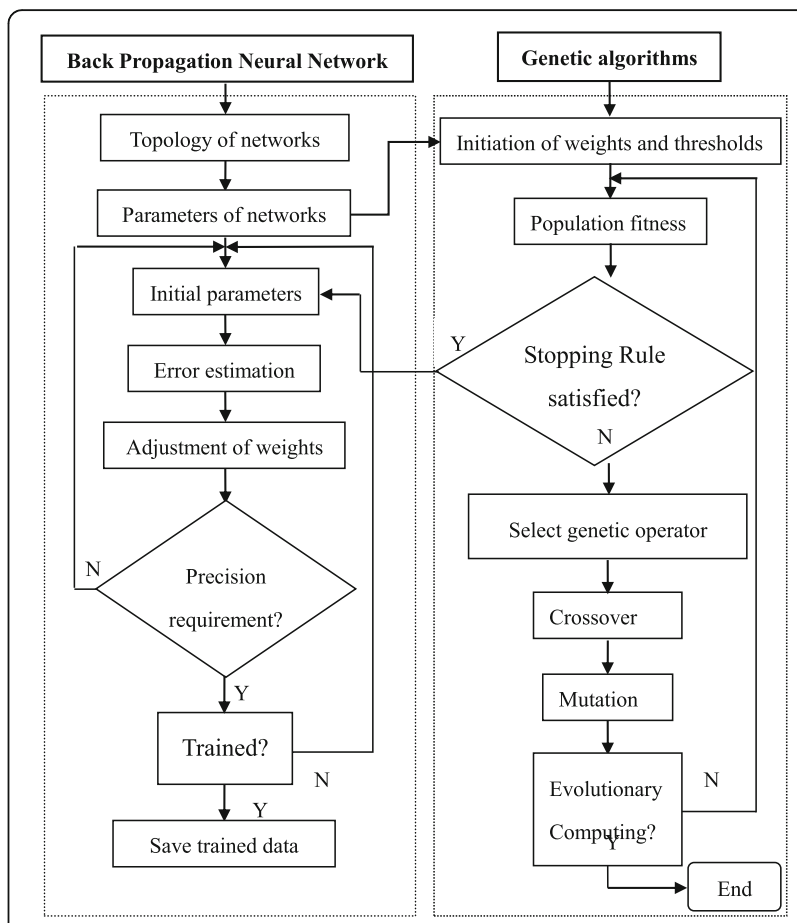

Fig. 10 Framework of GA-based BPNN

crossover and mutation operators of the genetic algorithm. This procedure is completed by applying a $\mathrm{BP}$ algorithm on the GA-established initial connection weights and thresholds. If the BP network's total mean squared error is larger than the expected error, the weights and thresholds will be updated; otherwise, they are saved as initial value of the BP network training. To train the BPNN, the learning rate was adjusted to follow Eq. 2 using the momentum and the self-adapting methods, which was programmed using Matlab.

$$
\operatorname{lr}(k+1)=\left\{\begin{array}{l}
1.05 \cdot \operatorname{lr}(k) ; \operatorname{mse}(k+1)<\operatorname{mse}(k) \\
0.7 \cdot \operatorname{lr}(k) ; \operatorname{mse}(k+1)>1.04 m s e(k) \\
\operatorname{lr}(k) ; \text { else }
\end{array}\right.
$$

where mse represents mean square errors for BPNN, and $k$ is training time.

Subsequently, they were further adjusted under the BP learning rule to the best result, by which the landslide susceptibility can be accurately predicted. The framework is shown in Fig. 11 for landslide susceptibility using GA-based BPNN.

Using BPNN modeling optimized by genetic algorithms, the parameters of GAs and neural networks are set in the present study. The population size is 100; crossover probability is 0.65 ; mutation probability is 0.01 ; momentum factor is 0.60 ; learning rate is 0.7 ; $\max$ learning number is 10000; and target error is 0.000001 . 


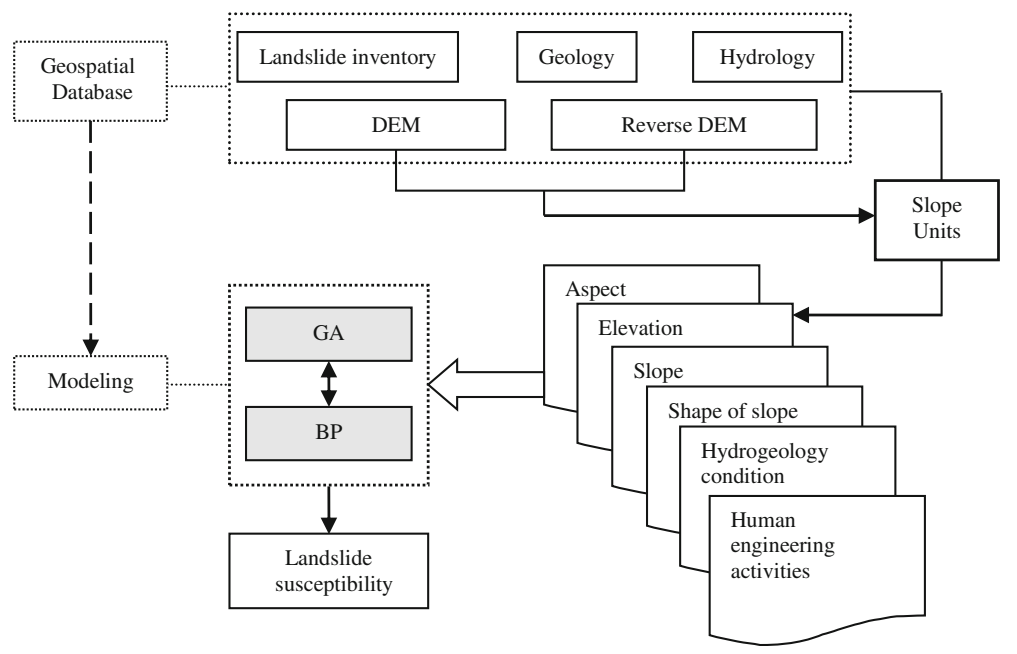

Fig. 11 Framework of landslide susceptibility using GA-based BPNN

From a database of 216 landslides in units of slope, 120 landslides were randomly used for training the neural network models, and 96 landslides were used for the validation of landslide susceptibility.

For the GA-improved BPNN, the error sum of the squares vs. the generation and fitness is shown in Figs. 12 and 13, respectively, in which red lines represent sampling data, and blue lines are present for training data. The final error is $9.96914 \mathrm{e}-007$ from the relationship of the epochs and errors in Fig. 14. It can be demonstrated that the requirement was met for the BPNN training for landslide susceptibility assessment.

\section{Results and discussion}

Following the process of mapping the slope units, the environmental factors can be categorized into slope, aspect, slope height, and the shape of the slope, human

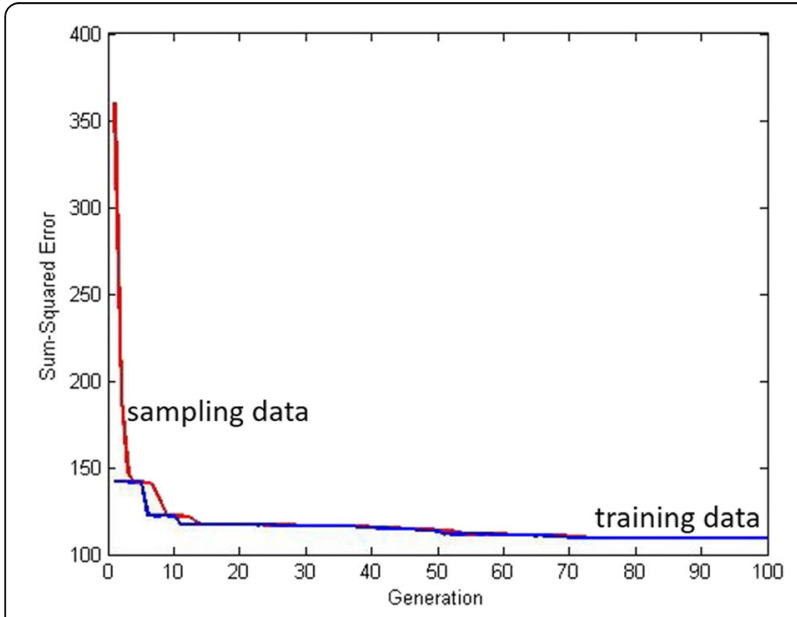

Fig. 12 The error sum of squares vs. generation activity and distance to river. These factors were statistically analyzed by slope units within the scope of GIS, after the construction of the geo-database. As mentioned above, the geological condition is almost the same in the study area, in which the strata in these units are mainly Neogene argillites, and the fluvial deposits consist of clayey silts and gravels and Quaternary loess. Due to human activity to effect the landslide susceptibility, it was simply determined by whether the slope area had been used for vegetation or not. The land use for vegetation needs more space and artificial excavation, even irrigation, then affecting the stability of landslides. With respect to the distance to river, the buffer of the Changshougou valley and drainages was selected for the analysis of susceptibility. A small number of landslides, which are closed to the river and drainage, can be in partial deformation, especially at

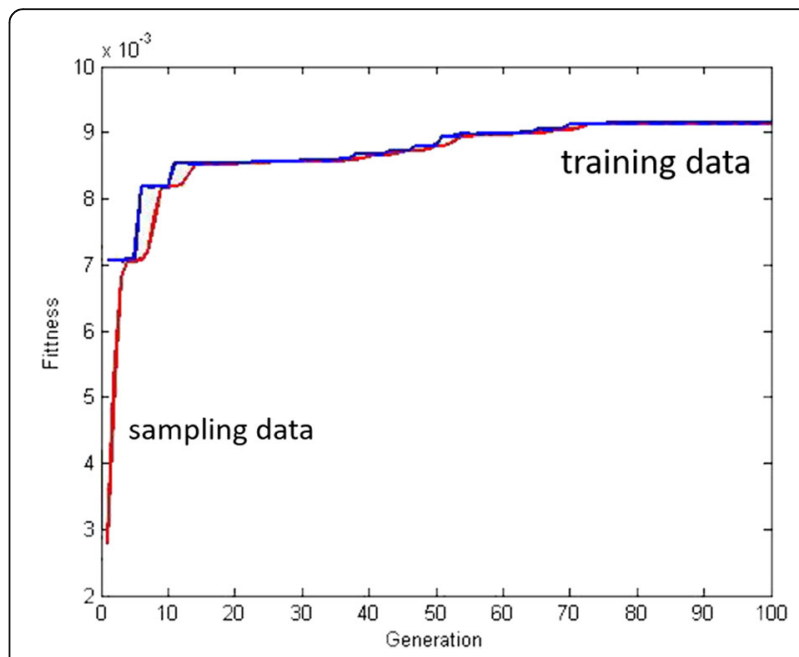

Fig. 13 Generation vs. fitness 


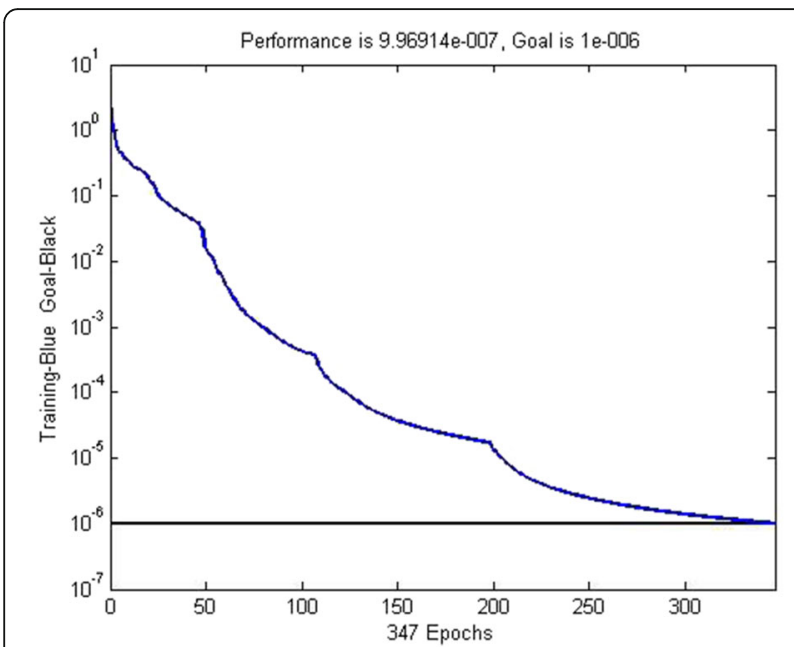

Fig. 14 The relationship between epochs and errors

the toe of slope due to erosion. The environmental factors are analyzed by focusing on the slope parameters, such as slope angle, aspect, height and the shape of the slope.

According to the statistical analysis, $36 \%$ of the landslides occurred on slopes with angles between $40^{\circ}$ and $50^{\circ}$, and $30 \%$ were occurred on slopes with angles from $50^{\circ}-60^{\circ}$ (Fig. 15). From the analysis of the relationships between the slope height and landslide occurrence (Fig. 16), almost $45 \%$ of the landslides occurred at elevations between 100 and $150 \mathrm{~m}$ (Fig. 17). It was also found that 38 and $56 \%$ of landslides were toward the southeast and southwest, respectively. However, five other variables made little contribution to the landslide occurrence. In addition, it was also demonstrated that the concave terrain was more stable, after large-scale landslides were observed to have occurred in the loess areas (Fig. 18).

After the GA-improved BPNN training, the susceptibility of landslides was predicted, as shown in Fig. 19. Comparing landslide occurrence with the susceptibility map, it was noted that 40 of 43 units were accurately

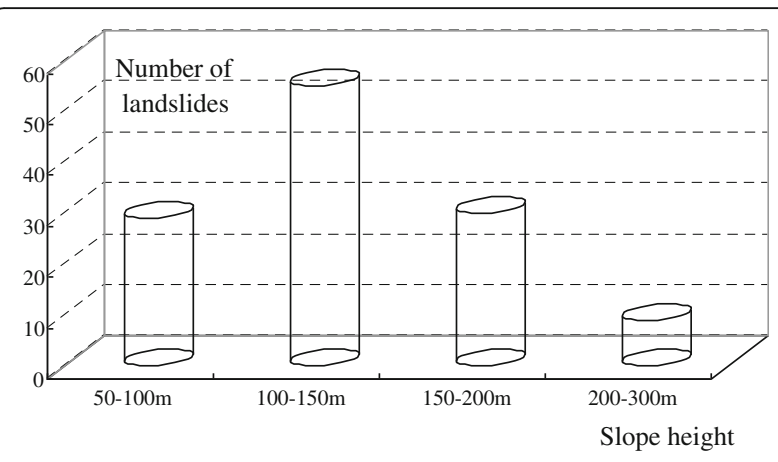

Fig. 16 Relationships between slope height and landslide occurrence

evaluated as occurrence of landslides after prediction by the GA-BPNN method, which means the accuracy of prediction is $93.02 \%$. Meanwhile, ten of 53 units without landslide occurrence is predicted to be sliding area, and the accuracy is $81.13 \%$. To sum up, the verification demonstrates satisfactory agreement with the accuracy of $86.46 \%$ obtained between the susceptibility map and landslide locations. In this case study, it was also found that some disadvantages can be overcome in the application of BPNN, such as low convergence rates and susceptibility to local minimums, after the optimization was carried out using GAs. To conclude, GA based BPNN are an effective method to predict landslide susceptibility with high accuracy.

Ten slopes (in yellow in Fig. 19) were predicted to be prone to landslides. In view of the environmental factors, all of these slopes were toward the southeast and southeast, were higher than $100 \mathrm{~m}$ and had slope angles greater than $43^{\circ}$. Furthermore, seven of the slopes were in convex topographic conditions, whereas the other slopes were located in concave topographic conditions.

As a useful tool, which addresses a nonlinear system and is capable of response to inputs and adaptation to the environment, the most widely used BPNNs are capable of evaluating landslide susceptibility at both the regional and site-specific scales (Lee et al. 2003; Neaupane and Achet 2004). BPNNs can be applied better over a wide

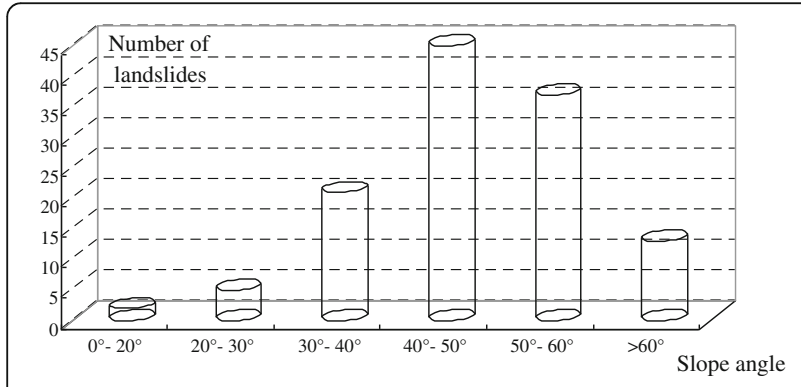

Fig. 15 Relationships between slope angle and landslide occurrence

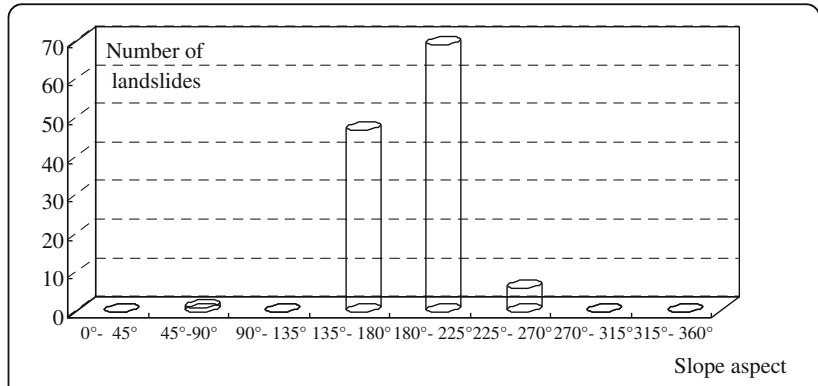

Fig. 17 Relationships between slope aspect and landslide occurrence 


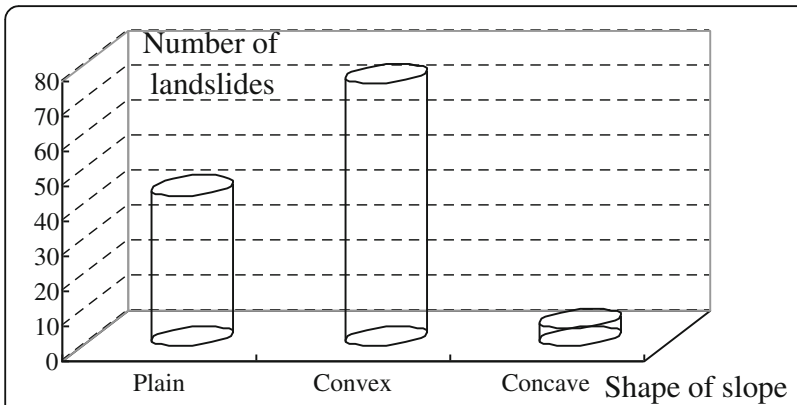

Fig. 18 Relationships between the shape of slope and landslide occurrence

area using non-parametric variables with large extensions. However, BPNNs are prone to falling into local extremes, and their convergence is slow. To overcome these drawbacks, a GA-based BPNN was proposed to optimize the neural network weights for landslide susceptibility assessment, and the topology was subjectively kept in three layers. In the optimization of the GA-based BPNN, the

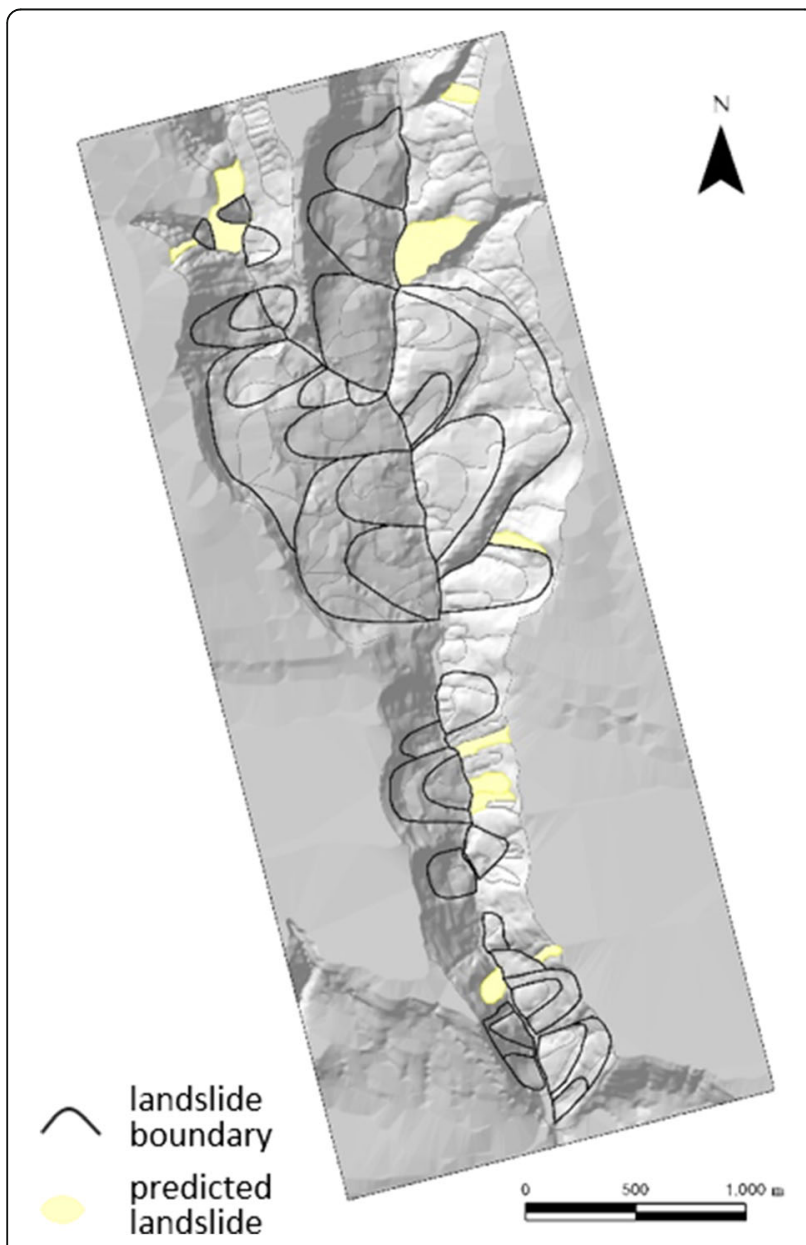

Fig. 19 Map with predicted landslide susceptibility (slopes potential to landslides in yellow) number of neurons can be decided in the hidden layer by the Kolmogorov theorem. For the training of the BPNN, the weights and thresholds were represented as genes of a chromosome, and the global optimum was then searched for using the selection, crossover and mutation operators of the genetic algorithm. To sum up, the advantages of using genetic algorithms were based on the performance of neural networks on the testing datasets, instead of only on the minimal square error in the modeling datasets. In addition, the minimal improvement of the genetic algorithms in this study occurred in the ratios between the numbers of chromosomes of a generation.

\section{Conclusions}

In this study, through the use of direct-reverse DEM technology, the Changshougou valley was divided into 216 slope units, of which 123 units included landslides. According to the mechanism analyses of the landslides in the loess area, six environmental factors were selected to evaluate landslide occurrence, such as slope height, slope angle, aspect, shape of slope, distance to rivers, and human activities. The spatial analysis shows that most of landslides in the Changshougou valley are located at an elevation of $100-150 \mathrm{~m}$, have a slope angle of $135^{\circ}-225^{\circ}$ and $40^{\circ}-60^{\circ}$ in the slope, and have convex slope conditions. After the spatial analysis of the environmental factors, a case study was presented for landslide susceptibility prediction using BPNN modeling optimized by genetic algorithms. From a database of 216 slopes, 120 units, including 80 with landslide presence and 40 without, were used for training the neural network models, and 96 slopes, i.e., 43 with landslide presence and 53 without landslide presence, were used for the validation of landslide susceptibility. Comparing landslide presence with a susceptibility map, it was noted that the prediction accuracy for landslide occurrence is $93.02 \%$, whereas units without landslide occurrence could be predicted with an accuracy of $81.13 \%$. It was also noted that 10 slopes were predicted to be prone to landslides. In view of the environmental factors, all of these slopes are toward southeast and southeast, are at an elevation greater than $100 \mathrm{~m}$, and have slope angles greater than $43^{\circ}$. It was also noted that seven of the slopes are in convex topographic conditions, whereas the other slopes are located in concave topographic conditions. Furthermore, the prediction of 10 slopes can be used as a general planning tool but is not intended for individual site-specific evaluations.

\section{Acknowledgements}

This research was supported by funding from the National Natural Science Foundation of China (No.41372296 and 41672267). A special note of appreciation is extended to the Ministry of National Science and Technology for their funding support (2012BAK10B00). Two anonymous reviewers were greatly appreciated for their comments and suggestions. 


\section{Authors' contributions}

HB carried out the improvement of GA-BPNN for landslide susceptibility, and drafted the manuscript as the corresponding author. JM carried out the data analysis for landslide susceptibility, and drafted parts of the manuscript. BZ carried out the GIS dataset preparation, and helped to draft the manuscript. YZ participated in the preparation of all figures. ZQ participated in the design of the methodology and performed the statistical analysis for landslide susceptibility. YP conceived of the study, and participated in its design and coordination and helped to draft the manuscript. All authors read and approved the final manuscript.

\section{Competing interests}

The authors declare that they have no competing interests.

\section{Publisher's Note}

Springer Nature remains neutral with regard to jurisdictional claims in published maps and institutional affiliations.

\section{Author details}

'School of Civil Engineering and Mechanics, Huazhong University of Science \& Technology, Wuhan 430074, People's Republic of China. ${ }^{2}$ Hubei Key Laboratory of Control Structure, Huazhong University of Science \& Technology, Wuhan 430074, People's Republic of China. ${ }^{3}$ Wenhua College, Wuhan 430074, People's Republic of China.

\section{Received: 19 September 2016 Accepted: 23 March 2017}

\section{Published online: 14 April 2017}

\section{References}

Ayalew, L., and H. Yamagishi. 2005. The application of GIS-based logistic regression for landslide susceptibility mapping in the Kakuda-Yahiko Mountains, central Japan. Geomorphology 65: 15-31.

Bai, S., G. Lu, J. Wang, P. Zhou, and L. Ding. 2011. GIS-based rare events logistic regression for landslide-susceptibility mapping of Lianyungang, China. Environmental Earth Sciences 62: 139-149.

Carrara, A., M. Cardinali, R. Detti, F. Guzzetti, V. Pasqui, and P. Reichenbach. 1991 GIS techniques and statistical models in evaluating landslide hazard. Earth Surface Processes Landforms 16: 427-445.

Catani, F., N. Casagli, L. Ermini, G. Righini, and G. Menduni. 2005. Landslide hazard and risk mapping at catchment scale in the Arno River basin. Landslides 2: 329-342.

Chung, C.F., and A.G. Fabbri. 2003. Validation of spatial prediction models for landslide hazard mapping. Natural Hazards 30: 451-472.

Chung, C.J. 2006. Using likelihood ratio functions for modeling the conditional probability of occurrence of future landslides for risk assessment. Computer and Geosciences 32: 1052-1068.

Conforti, M., S. Pascale, G. Robustelli, and F. Sdao. 2014. Evaluation of prediction capability of the artificial neural networks for mapping landslide susceptibility in the Turbolo River catchment (northern Calabria, Italy). Catena 113: 236-250.

Dahal, R.K., S. Hasegawa, A. Nonomura, M. Yamanaka, S. Dhakal, and P. Paudyal. 2008. Predictive modelling of rainfall-induced landslide hazard in the Lesser Himalaya of Nepal based on weights-of-evidence. Geomorphology 102: 496-510.

Derbyshire, E., J.T. Wang, and X.M. Meng. 1999. A treacherous terrain: background to natural hazards in northern China, with special reference to the history of landslides in Gansu Province. In Landslides in the thick loess terrain of northwest China, ed. E. Derbyshire, X.M. Meng, and T.A. Dijkstra, 11-18.

Ercanoglu, M., and C. Gokceoglu. 2002. Assessment of landslide susceptibility for a landslide-prone area (north of Yenice, NW Turkey) by fuzzy approach. Environ Geol 41: 720-730.

Ermini, L., F. Catani, and N. Casagli. 2005. Artificial Neural Networks applied to landslide susceptibility assessment. Geomorphology 66: 327-343.

Fell, R., J. Corominas, C. Bonnard, L. Cascini, E. Leroi, and W.Z. Savage. 2008 Guidelines for landslide susceptibility, hazard and risk zoning for land use planning. Engineering Geology 102: 85-98.

García-Rodríguez, M.J., and J.A. Malpica. 2010. Assessment of earthquaketriggered landslide susceptibility in El Salvador based on an Artificial Neural Network model. Nat. Hazards Earth Syst. Sci. 10: 1307-1315.

Gómez, H., and T. Kavzoglu. 2005. Assessment of shallow landslide susceptibility using artificial neural networks in Jabonosa River Basin, Venezuela. Engineering Geology 78: 11-27.
Guzzetti, F., A. Carrara, M. Cardinali, and P. Reichenbach. 1999. Landslide hazard evaluation: a review of current techniques and their application in a multiscale study, Central Italy. Geomorphology 31: 181-216.

Hasekiogullar, G.D., and M. Ercanoglu. 2012. A new approach to use AHP in landslide susceptibility mapping: a case study at Yenice (Karabuk, NW Turkey). Natural Hazards 63: 1157-1179.

Holland, J.H. Adaptation in natural and artificial systems. Ann Arbour: The University of Michigan Press, 1975.

Kanungoa, D.P., M.K. Arorab, S. Sarkara, and R.P.A. Guptac. 2006. Comparative study of conventional, ANN black box, fuzzy and combined neural and fuzzy weighting procedures for landslide susceptibility zonation in Darjeeling Himalayas. Engineering Geology 85: 347-366.

Kavzoglu, T., E.K. Sahin, and I. Colkesen. 2015. Selecting optimal conditioning factors in shallow translational landslide susceptibility mapping using genetic algorithm. 192: 101-112.

Kesign, U. 2004. Genetic algorithm and artificial neural network for engine optimisation of efficiency and NOx emission. Fuel 83: 885-895.

Lee, S., J.H. Ryu, K. Min, and J.S. Won. 2003. Landslide susceptibility analysis using GIS and artificial neural network. Earth Surface Processes and Landforms 23: $1361-1376$

Lee, S., and D. Pradhan. 2010. Regional landslide susceptibility analysis using back-propagation neural network model at Cameron Highland, Malaysia. Landslides 7(1): 13-30.

Madaeni, S.S., N.T. Hasankiadeh, A.R. Kurdian, and A. Rahimpour. 2010. Modeling and optimization of membrane fabrication using artificial neural network and genetic algorithm. Separation of Purification Technology 76: 33-43.

Maidment, D. 2002. Arc Hydro: GIS for water resources. ESRI 380, New York Street, Redland, California.

Martinovic, K., K. Gavin, and C. Reale. 2016. Development of a landslide susceptibility assessment for a rail network. Engineering Geology 215: 1-9.

Melchiorre, C., M. Matteucci, A. Azzoni, and A. Zanchi. 2008. Artificial neural networks and cluster analysis in landslide susceptibility zonation. Geomorphology 94: 379-400.

Meng, X. M., Dijkstra, T. D., Derbyshire, E. 2000. Loess slope instability. In: Derbyshire E, Meng, X.M., Dijkstra, T.A. (eds). Landslides in the thick loess terrain of north-west China, 175-181. Chichester: John Wiley.

Neaupane, K.M., and S.H. Achet. 2004. Use of back propagation neural network for landslide monitoring: a case study in the higher Himalaya. Engineering Geology 74: 213-226.

Nefeslioglu, H.A., C. Gokceoglu, and H. Sonmez. 2008. An assessment on the use of logistic regression and artificial neural networks with different sampling strategies for the preparation of landslide susceptibility maps. Eng. Geol. 97: 171-191.

Nefeslioglua, H.A., C. Gokceoglub, H. Sonmez, and T. Gorum. 2011. Medium-scale hazard mapping for shallow landslide initiation: the Buyukkoy catchment area (Cayeli, Rize, Turkey). Landslides 8(4): 459-483.

Nourani, V., B. Pradhan, H. Ghaffari, and S.S. Sharifi. 2014. Landslide susceptibility mapping at Zonouz Plain, Iran using genetic programming and comparison with frequency ratio, logistic regression and artificial neural network models. Nat. Hazards 71: 523-547.

Peng, S.Z., and Z.T. Guo. 2007. Clay mineral composition of the Tertiary red clay and the Quaternary loess-palaeosols as well as its environmental implication. Chinese J. Quaternary Science 27: 277-285.

Pham, B.T., D.T. Bui, I. Prakash, and M.B. Dholakia. 2017. Hybrid integration of Multilayer Perceptron Neural Networks and machine learning ensembles for landslide susceptibilityassessment at Himalayan area (India) using GIS. CATENA 149: 52-63.

Rumelhart, D.E., and J.L. McClelland. 1986. Parallel Distributed processing: Exploration in the Microstructure of Cognition. Cambridge: MIT-Press.

Sexton, R.S., and J.N.D. Gupta. 2000. Comparative evaluation of genetic algorithm and back propagation for training neural networks. Inform. Sciences 129: 45-59.

Van Westen, C.J. 1994. GIS in landslide hazard zonation: a review, with examples from Andes of Colombia. In Mountain Environments and Geographic Information Systems, ed. M. Price and I. Heywood, 135-165. Basingstoke: Taylor \& Francis.

Wang, H.B., G.J. Liu, W.Y. Xu, and G.H. Wang. 2005. GIS-based landslide hazard assessment: An overview. Progress in Physical Geography 29: 548-567.

Xie, M.W., T. Esaki, and G.Y. Zhou. 2004. GIS-based probabilistic mapping of landslide hazard using a three-dimensional deterministic model. Natural Hazards 33: 265-282. 
Yilmaz, Y. 2009. An Agent Simulation Study on Conflict, Community Climate, and Innovation in Open Source Communities. International Journal of Open Source Software and Processes 1(4): 1-25.

Zhang, A.L., Z.T. Yang, J. Zhong, and F.S. Mi. 1995. Characteristics of late Quaternary activity along the southern border fault zone of Weihe graben basin. Quaternary International 25: 25-31.

\section{Submit your manuscript to a SpringerOpen ${ }^{\circ}$} journal and benefit from:

- Convenient online submission

- Rigorous peer review

- Immediate publication on acceptance

- Open access: articles freely available online

- High visibility within the field

- Retaining the copyright to your article

Submit your next manuscript at springeropen.com 